\title{
EL NIÑO VESTIDO DE ECLESIÁSTICO DE MAZO: ¿RETRATO DE PRIMERA COMUNIÓN U OBISPILLO CATEDRALICIO?
}

El cuadro que ilustra este artículo (Fig. 5) es bastante conocido ya que se tiene por uno de los mejores ejemplares dentro de la irregular producción de Juan Martínez del Mazo si es que pertenece a su mano ${ }^{1}$. Su calidad evidente, su procedencia de la prestigiosa colección Harrach de Viena —en donde todavía lo registraba Gaya Nuño como obra de Velázquezen su libro catálogo La Pintura Española fuera de España de 1958, bajo el n. ${ }^{\circ} 1724$, y, ¿cómo no?, la aparente rareza de su tema expresada en el título le han conferido una popularidad que creemos justifican estas líneas que espero orienten en la dirección adecuada la polémica sobre lo que verdaderamente representa esta pintura del diminuto personaje.

El cuadro, en la actualidad, forma parte de la colección de pintura española del Museo de Toledo (Ohio) por legado de Edward Drummond Libbey. En el Museo se da como procedencia Frederick Mont, Nueva York y antes Colección Harrach de Viena donde estuvo desde el siglo XVII hasta 1950. Fue expuesto en 1982 formando parte de la exposición Painting in Spain 1650-1700, presentada en los museos de la Universidad de Princeton y del Instituto de Arte de Detroit. En Princeton lo ví yo cuando la inauguración y puedo recordar que fue una de las pinturas que congregaba más público y que expertos de arte e historia de España debatían entre divertidos y frustrados el significado e identidad del niño vestido con exceso de pompa eclesial.

En el catálogo de la exposición preparado y escrito por Edward J. Sullivan y Nina A. Mallory con un ensayo histórico de J. T. Elliot, se dice en la notas a este cuadro que la identidad de este niño ha intrigado a muchos escritores pero que no se ha formulado ninguna explicación totalmente convincente. $\mathrm{Y}$ añade que ciertamente debía de tratarse de una persona importante para que fuera retratada, vestida con lo que parecen ser las ropas de un cardenal ${ }^{2}$.

La posible solución a este enigma nos viene de labios de Picasso. Éste, al recordar los años de su infancia vividos en La Coruña reveló a algunos de sus amigos como Jaime Sabartés que recibió la Primera Comunión en esta ciudad y que la hizo vestido de obispillo. Josep Palau i Fabre, su biógrafo semi-oficial y principal especialista de Picasso en España, trató personalmente con Picasso este tema: «Durante uno de aquellos años escolares de La Coruña, Picasso hizo la primera comunión. Aquí era costumbre que, en tal ocasión, los niños fueran vestidos de obispillo o cardenal. Según nos ha explicado el propio Picasso, él vistió de obispillo» ${ }^{3}$. No es ésta la única vez que Picasso ha recordado esta curiosidad de su infancia en A Coruña.

Al tropezar de nuevo recientemente con la ilustración del cuadro del niño del museo americano lo relacioné con el traje de «obispillo» de Pablito Ruiz Picasso. A partir de este revelación el personajillo del cuadro de Ohio desvela su verdadera identidad. En efecto: Se trata -así lo creeo yo - de un niño vestido de Primera Comunión. Obsérvese como la manecita derecha agarra un librito devocionario y compárese con las fotografías que reflejan

1 Ver la relación de citas ae autores al pie de la nota al cuadro n. ${ }^{\circ} 21$ en la exposición de Princeton-Detroit. Los autores antiguos - Waagen, Curtis, Baldry, Lefort...- en general lo creían de Velázquez. Pero desde Beruete en 1909 la atribución casi unánimemente aceptada es la de Juan B. Martínez del Mazo, yerno de Velázquez. Carreño es el nombre propuesto por Camon y Barretini. (Painting in Spain 1650-1700 from North American Collections, Princeton 1982).

2 Ibid. pp. 80-81. Nina Ayala Mallory en «Juan Bautista Martínez del Mazo: Retratos y Paisajes», artículo publicado en Goya n..$^{\circ} 221$, p. 265, lo reproduce como «Niño con vestimenta eclesiástica».

3 Josep Palau i Fabre: Picasso vivo (1881-1907), p. 49. 
este tradicional rito español incluso con los casi actuales niños vestidos de marino y se caerá en la semejanza de la situación. El búcaro con flores, el lacito blanco prendido al pecho y el tono general del cuadro reflejan un ambiente de celebración festiva no exenta de solemnidad que traiciona un tanto el pintor al hacer colgar de la otra mano del niño un bonete demasiado grande para su cabeza. A la derecha al fondo se distingue un paisaje con figuras que recuerda los ambientes de los cuadros palaciegos velazqueños. Entonces este cuadro no es un simple retrato si no más bien un cuadro de costumbres. Evidentemente no se trata del retrato de un Cardenal Infante y ningún autor ha señalado esta posibilidad. Estaría mejor trajeado. En el Museo del Prado existe un claro ejemplo de este tipo de retratos: el del último hijo varon de Felipe V, don Luis Antonio, pintado por L.Michel Van Loo a la edad de ocho años cuando fue promovido a la silla arzobispal de Toledo en 1715 recibiendo al mismo tiempo la púrpura cardenalicia. Mucho más solemne y atildado que el rapaz del cuadro de Ohio.

Aunque bien pudiera tratarse de un niño noble del entorno de la familia real ${ }^{4}$ nos inclinamos a pensar que se trata de un hijo del artista. Probablemente Mazo, que hizo casi toda su carrera al servicio del Rey, quiso conmemorar en el lienzo la primera comunión de uno de sus hijos que podría haberse celebrado en las dependencias domésticas de Palacio. Este hijo bien pudiera ser - si se acepta previamente que ambos cuadros fueron pintados hacia el mismo tiempo- el niño calzado con botas de mosquetero situado en el centro del conocido cuadro de la Familia del Pintor del museo de Historia del Arte de Viena que tiene rasgos muy semejantes - amplia melena color castaño y ojos grandes- al representado en esta pintura. Pero también pudiera ser otro de ellos.

Una vez en nuestra mente esta interpretación lo difícil es encontrar testimonios documentales que la abonen y la sustenten. Los ritos y ceremonias católicos contrấreformistas estaban en pleno vigor en la España de Felipe IV y se prolongan con notable persistencia hasta por lo menos 1950 gracias al ambiente inmovilista de la España de Franco ${ }^{5}$. (A falta de un testimonio gráfico más preciso publico aquí una fotografía de hacia 1910 procedente del mercadillo dominical de la Plaza Mayor de Madrid) (Fig. 6). El Concilio de Trento potenció la Eucaristía proclamando la doctrina de la transustanciación y regulando como debía recibirse la Comunión. Pero en la extensa bibliografía eucarística que he revisado no he encontrado pista alguna sobre los vestidos de los primero-comulgantes. En Francia se organizaban grandes ceremonias colectivas. La costumbre española de vestir a los comulgantes masculinos con ropajes de eclesiásticos o de frailes y a las niñas con hábitos monjiles, que normalmente sunministraba la propia parroquia, se remonta conocidamente a los principios del siglo XIX pero no hay seguridad de que el rito se celebrara así dos siglos antes, es decir en la época en que fue pintado el cuadro.

Tęófanes Egido, catedrático de Historia Moderna de la Universidad de Valladolid a quien consulté verbalmente, duda que se celebrara la Primera Comunión en esas lejanas fechas y propone una interpretación alternativa del tema de nuestro cuadro: puede tratarse de un niño vestido de «obispillo» pero no para recibir la primera comunión sino más bien para ejercer de «obispillo» ${ }^{6}$. La fiesta de los «obispillos» que tenía lugar bien en Navidad o en los

4 Por la pose y los elementos accesorios recuerda al retrato de la Infanta Margarita de Velázquez del Museo de Historia del Arte de Viena. Tambien observado por Nina Mallory en el mencionado artículo que considera «este retrato», «uno de los cuadros más atractivos de Mazo».

5 En los años cuarenta durante la postguerra española, en algunas regiones, los niños comulgantes vestían y aún hoy sigue aunque disminuida esta práctica, hábitos muy sencillos de colores claros de monjes o monjas según el sexo.

${ }_{6}$ T. Egido me informa que Antonio Cabeza profesor de la misma Universidad prepara un estudio sobre la fiesta de los obispillos. 


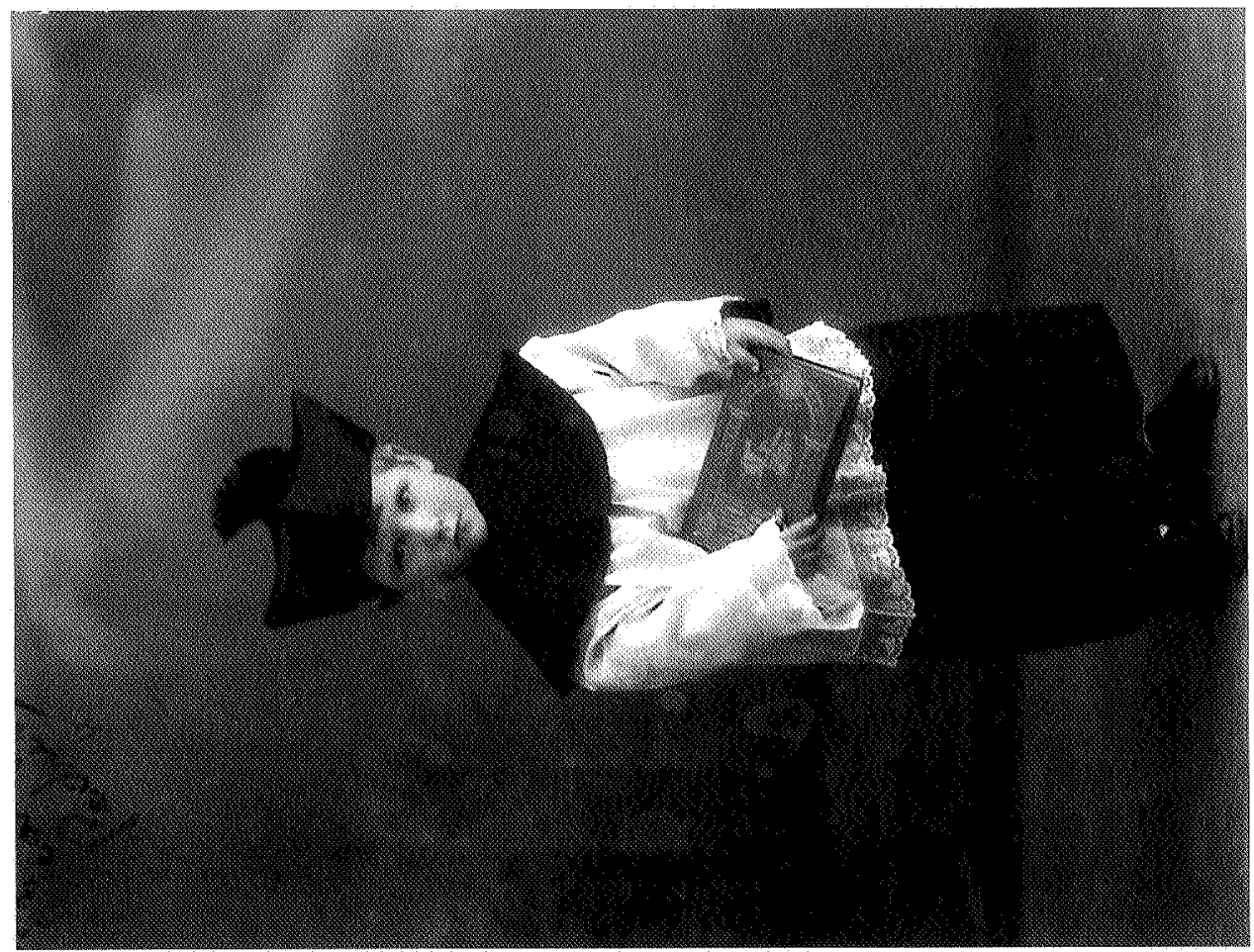

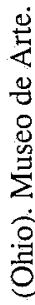

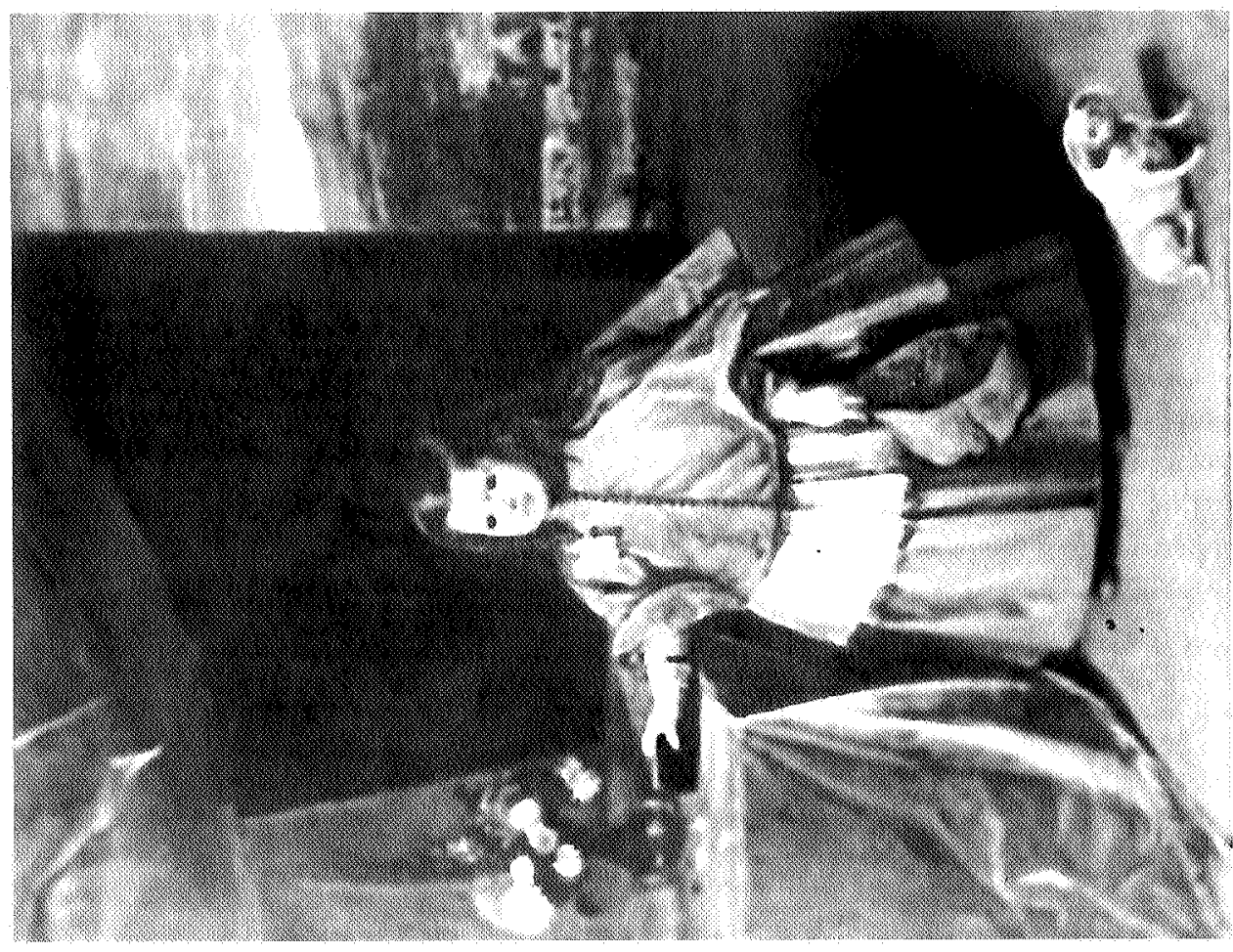

원

ค ภ

:

논

:

覀

ปั

8 赵

窇

를

跤

$0 \cdot \tilde{5}$

สู ฐ

\&

政

氖

焉

$\sum 0$

芯 :

节

$\infty$

哥

in

冚苛

它江 
carnavales, era tradicional en muchas ciudades españolas desde la Edad Media como un juego o desahogo infantil tolerado. Según el Espasa, la primera acepción de obispillo es: «Muchacho que en algunas catedrales viste de obispo la víspera y día de San Nicolás de Bari» ${ }^{7}$.

\section{ENRIQUE GARCÍA-HERRAIZ}

Miembro de A.I.C.A.

\section{UN LIENZO DE LOS SENTIDOS DE JEAN COSSIERS}

A Jean Cossiers se le atribuye este lienzo de colección privada en Madrid (Fig. 7), pintor del ámbito de Rubens, del que conocemos tres lienzos en el Museo del Prado, (n. ${ }^{\text {ss }}$ 1463, 1464, 1465), pero copias de bocetos de Rubens para la decoración de la Torre de la Parada ${ }^{1}$, para lo que el pintor fue seleccionado por el Cardenal Infante entre los más destacados de la escuela de Amberes, bajo la dirección de Rubens.

Un cuarto lienzo está en el Palacio Real, identificado por quien esto escribe ${ }^{2}$. Todas son obras para el mismo conjunto, y afines a la estética del barroco del maestro; pero la pintura que aquí se da a conocer es diferente, pues corresponde a la etapa tenebrista del pintor y de invención propia. El acierto de esta composición vivaz y receptiva, de belleza cromática y gestos expresivos, fue motivo de varias réplicas, cuyo conocimiento ha contribuido a esclarecer la paternidad de la que se estudia aquí.

sa

El joven lo repite en el n. ${ }^{\circ} 38$ del Museo de Amberes, la Sagrada Familia del Louvre y Alegorías de las galerías Marcus Bens y R. Grem de Londres; y la mujer es la misma en la versión de la colección de Sir Félix Cassel (Fig. 8), duque de Albercort (L.128 X 191) ${ }^{3}$. Debió gustar esta composición, pues Cossiers hizo una tercera réplica, que poseyó $\mathrm{K}$. Loevench en Nueva York ${ }^{4}$.

Las figuras de medio cuerpo siguen esquemas de Caravaggio, pero esto es frecuente en el siglo XVI, lo hace Massys con un tema igual: los Sentidos del Museo de Estocolmo. Aquí reviven las mismas imágenes y con igual intencionalidad. Más próxima es la versión de Finsonius en el Erzog Antón Ulbrich Museum, y los grabados de A. Collaert, según A. Van Noort. J. Cossiers pudo conocerlos.

Estamos frente a una alegoría de los Sentidos cuyo contenido fue desconocido. Los personajes - de diferentes edades- no llevan signos alegóricos, tan típicos en los grabados italianos y flamencos de los siglos XVI y XVII, igual que en Caravaggio y satélites los omite, asumiendo la realidad desnuda, lo que dificulta la lectura de su mensaje.

7 En la catedral de Sevilla la víspera del día de los Inocentes, en la Navidad, se elegía como obispillo al menor de los niños cantores llamados seises, el cual, seguido de una grotesca corte, al oirse cierto versículo del canto Magnificat, desalojaba en medio del jolgorio popular a los viejos canónigos de sus sillas del coro (Diccionario Enciclopédico Espasa).

1 Díaz Padrón, M.: El Siglo de Rubens en el Museo del Prado, Madrid 1995, I, p. 374.

2 Díaz Padrón, M.: Homenaje a P. P. Pablo Rubens (1977-1978), Palacio de Velázquez, p. 39, n. 16.

3 Vendido a Christie's (Londres, 21, I, 1954, n. ${ }^{\circ} 150$ ).

4 Dayton, Art Institut ( . $^{\circ}$ 55.74), legado Robert Badenshon, vendido en la galería Christie's de Nueva York (19-1-1984, n. $\left.{ }^{\circ} 58\right)$. 